\title{
A experimentação teórico-prática do aluno de Terapia Ocupacional no campo social: uma vivência com a população em situação de rua
}

\author{
The theoretical-practical experimentation of an \\ Occupational Therapy student in social field: \\ an experience with homeless people
}

\author{
Roseli Esquerdo Lopes ${ }^{1}$, Ariane Machado Palma², \\ Tiy de Albuquerque Maranhão Reis ${ }^{3}$
}

\begin{abstract}
LOPES, R. E.; PALMA, A. M.; REIS, T. A. A experimentação teórico-prática do aluno de Terapia Ocupacional no campo social: uma vivência com a população em situação de rua. Rev. Ter. Ocup. Univ. São Paulo, v. 16, n. 2, p. 54-61, maio/ago., 2005.

RESUMO: A questão da articulação entre teoria e prática permanece como desafio central para uma melhor graduação profissional, apesar dos quase cinqüenta anos de formação de terapeutas ocupacionais no Brasil. Nos seus diversos campos ou áreas de atuação, a formação acadêmica do terapeuta ocupacional vem se transformando, seja pelos avanços tecnológicos e de conhecimento, seja pelas políticas públicas que se estabelecem ou, ainda, pelo enorme escopo de ações de organizações não-governamentais que continuam fazendo parte da trajetória dos grupos populacionais para os quais a terapia ocupacional brasileira se volta. Por outro lado, as necessidades presentes na desigual e complexa realidade social têm demandado um profissional preparado para atuar/intervir em diferentes setores da sociedade, em situações que extrapolam os espaços desenhados pelos eixos "saúde e doença". Os estudos e debates acerca da composição das matrizes curriculares da graduação e das suas reformulações têm aberto possibilidades para a inclusão de novas áreas e/ou temáticas, através de disciplinas cujos conteúdos buscam dotar o terapeuta ocupacional de capacidades e habilidades que lhe permitam compreender, refletir, propor e implementar ações no campo social. Nessa perspectiva, apresenta-se a experiência do estágio profissional em terapia ocupacional no campo social junto à população em situação de rua, oferecido a alunos da Universidade Federal de São Carlos pelo Núcleo USP/UFSCar do Projeto Metuia. Suas análises e conclusões vêm se somar à defesa da importância da terapia ocupacional social como disciplina curricular na formação acadêmica de graduação do terapeuta ocupacional, bem como apontar para diferentes possibilidades de intervenção.
\end{abstract}

DESCRITORES: Educação superior. Responsabilidade social. Terapia ocupacional/tendências. Terapia ocupacional/educação. Currículo.

\footnotetext{
${ }^{1}$ Professora Adjunta do Departamento de Terapia Ocupacional e do Programa de Pós-Graduação em Educação da Universidade Federal de São Carlos (UFSCar). Coordenadora do Núcleo USP/UFSCar do Projeto Metuia. Doutora em Educação pela Universidade Estadual de Campinas.

${ }^{2}$ Graduanda em Terapia Ocupacional da UFSCar, integrando o Programa Unificado de Iniciação Científica da UFSCar.

${ }^{3}$ Terapeuta Ocupacional da Associação Minha Rua Minha Casa e do Núcleo USP/UFSCar do Projeto Metuia.

Endereço para correspondência: Laboratório Metuia do Departamento de Terapia Ocupacional da UFSCar. Via Washington Luis, Km 235 - São Carlos, SP. CEP: 13565-905. relopes@ power.ufscar.br
} 


\section{INTRODUÇÃO}

$\mathrm{E}$ m quase cinqüenta anos de formação de terapeutas ocupacionais no Brasil, a questão da articulação entre teoria e prática permanece como desafio central para uma melhor graduação profissional (HAHN e LOPES, 2003, LOPES, 2004a). Nos seus diversos campos ou áreas de atuação, a formação acadêmica vem se transformando, seja pelos avanços tecnológicos e de conhecimento, seja pelas políticas públicas que se estabelecem, especialmente, na área da saúde e dos desdobramentos da consolidação do Sistema Único de Saúde, ou, ainda, pelo enorme escopo de ações de organizações não-governamentais (de caráter público ou não) que continuam fazendo parte da trajetória dos grupos populacionais para os quais a terapia ocupacional brasileira se volta. Por outro lado, as necessidades presentes na desigual e complexa realidade social brasileira têm demandado um profissional preparado para atuar/intervir em diferentes setores da sociedade, em situações que extrapolam os espaços desenhados pelos eixos "saúde e doença”.

Dessa forma, as discussões acerca da composição das matrizes curriculares da graduação e das suas reformulações abriram possibilidades para a inclusão de novas áreas e/ou temáticas, através de disciplinas cujos conteúdos buscam dotar o terapeuta ocupacional de capacidades e habilidades que lhe permitam compreender, refletir, propor e implementar ações no campo social.

Nessa perspectiva, apresentamos o relato da experiência do estágio profissional em terapia ocupacional no campo social, oferecido aos alunos de último ano do Curso de Graduação em Terapia Ocupacional da Universidade Federal de São Carlos - UFSCar.

Desde 2000, através do Núcleo USP/UFSCar do Projeto Metuia $^{1}$, os alunos de terapia ocupacional de ambas universidades podem realizar estágios nos locais de intervenção do núcleo. Entretanto, no caso da UFSCar, os alunos não contam em seu projeto pedagógico obrigatório com disciplinas teóricas, ou teórico-práticas, acerca da atuação no campo social; a possibilidade de contato formalizado, via estrutura curricular, fica restrita à disciplina "Estágio Profissional em Terapia Ocupacional", conforme detalharemos a seguir.

Assim, a experimentação teórico-prática do aluno, por meio da vivência com a população em situação de rua, permite discutir a importância da terapia ocupacional social como disciplina curricular na formação acadêmica de graduação do terapeuta ocupacional, além de apontar para novas possibilidades de intervenção.

\section{Pressupostos da terapia ocupacional social}

Conforme Lopes (1999), a partir dos anos 70 e 80, a crítica ao desenvolvimento da assistência em saúde e em reabilitação, feita por movimentos sociais, coloca em cena demandas de atenção em relação à saúde mental, à saúde da pessoa com deficiência, aos idosos, às crianças e aos adolescentes, dentre outros grupos populacionais. Tratase do questionamento, nesse momento, da centralidade da assistência hospitalar e de caráter asilar para alguns daqueles grupos e filantrópica e beneficente para outros, bem como de discussões acerca da necessidade de implementação de políticas sociais para ampliar o acesso à saúde, à educação, ao trabalho e a melhores condições de vida para a população.

\begin{abstract}
Nesse contexto, terapeutas ocupacionais passam a propor e desenvolver ações territoriais, comunitárias e extrahospitalares, cujas tendências, orientações e preocupações necessitam de sistematização. Um dos eixos que vem a se constituir é o da crítica à organização de serviços e de propostas assistenciais. Aponta-se a necessidade de uma agenda de políticas sociais que considere as demandas daqueles grupos populacionais. Outro é o da reflexão sobre a atomização do saber e sobre as estratégias reducionistas de abordagens de questões complexas, que terminam por reduzir a pessoa que sofre aos próprios sinais e manifestação da dor, da incapacidade ou de suas desvantagens (BARROS, 1991 apud BARROS et al., 2002, p. 366).
\end{abstract}

Procurando construir uma apreensão aprofundada dessas questões, o Projeto Metuia defende a necessidade de uma abordagem complexa pela terapia ocupacional de problemáticas a ela vinculadas, e recoloca a proposição de uma área social no campo da terapia ocupacional:

retomando os movimentos sociais e os processos de desinstitucionalização que favoreceram o desenvolvimento da atenção extra-clínica em terapia ocupacional, através de um diálogo privilegiado com as ciência humanas; problematizando o conceito de atividade, a partir de uma perspectiva que o inscreva num contexto sócio-cultural, o

\footnotetext{
${ }^{1}$ Grupo interinstitucional de estudos, formação e ações pela cidadania de crianças, adolescentes e adultos em processos de ruptura das redes sociais de suporte, do qual participam docentes, discentes e profissionais da área de terapia ocupacional de três Universidades paulistas: Pontifícia Universidade Católica de Campinas, Universidade Federal de São Carlos e Universidade de São Paulo, além de terapeutas ocupacionais das cidades de Campinas, São Carlos e São Paulo.
} 
qual atribui sentidos particulares e específicos à atividade; analisando as políticas públicas voltadas para a população alvo da terapia ocupacional, assim como a organização dessa população para a defesa e a garantia de seus direitos; propondo métodos de abordagem que permitam trabalhar as atividades em terapia ocupacional como instrumento de emancipação pessoal e social (BARROS et al., 2002, p. 366).

A terapia ocupacional social busca um maior compromisso com a população que assiste por meio do conhecimento da sua realidade, das suas necessidades e das maneiras pelas quais as pessoas compreendem o seu mundo e o seu cotidiano. Promove um espaço para reflexões das possibilidades e limites da atuação na atenção a grupos sociais em processos de rupturas das redes sociais de suporte, exigindo um perfil profissional aberto às necessidades do outro, esse outro, aliás, contextualizado e em permanente relação com um meio que o produz e é produzido por ele, no qual o terapeuta ocupacional também participa e intervém (BARROS et al., 2002).

\section{A matriz curricular da terapia ocupacional e o contato com atividades extracurriculares na graduação da UFSCar}

O Curso de Graduação em Terapia Ocupacional da UFSCar está dividido em três ciclos de disciplinas: básicas (área de ciências biológicas e ciências humanas); préprofissionalizantes; aplicadas e estágios profissionais, sendo este último composto por três disciplinas obrigatórias dos $7^{\circ}$ e $8^{\circ}$ semestres. A carga horária mínima por disciplina referente ao estágio é de 240 horas, sendo necessário o cumprimento de no mínimo três, perfazendo, portanto, um total de 720 horas.

Os estágios são distintos em suas especificidades. No primeiro deles, o aluno atua na área de psiquiatria e saúde mental. No segundo, na área de disfunções físicas. E, no terceiro, a área é de livre escolha. Essa 'livre escolha' é direcionada, pois o aluno não deve repetir a área e a faixa etária de cada um dos estágios anteriores e recomenda-se a experimentação de um novo campo e/ou a atuação em uma outra área e/ou população e/ou faixa etária (CCTO, 2003).

Sendo assim, somente por meio de atividades extracurriculares, especialmente aquelas desenvolvidas pelo Núcleo USP/UFSCar do Projeto Metuia junto aos alunos da UFSCar, estes têm a oportunidade de aproximar-se e de conhecer as bases teóricas e as experiências práticas da terapia ocupacional no campo social. Tais atividades vão desde a orientação bibliográfica até a participação em pesquisa de programas de iniciação científica e em projetos de extensão. Destaca-se o projeto "Estudos e Discussões em Terapia Ocupacional Social" do Laboratório Metuia do Departamento de Terapia Ocupacional da UFSCar, iniciado em 2000, com encontros mensais que, a partir da leitura de textos subsidiários, aulas expositivas e dialogadas, debates em grupos e subgrupos, trabalha temas como: o desenvolvimento da terapia ocupacional territorial e comunitária; o campo de ação da terapia ocupacional social e o trabalho técnico junto a populações em processos de ruptura das redes sociais de suporte; a atividade como instrumento de significação/ressignificação e emancipação pessoal e social; experiências de intervenção concreta (LOPES, 2004b). Essas atividades, embora não obrigatórias, fazem parte do projeto pedagógico do Curso desde $1999^{2}$.

\section{Estágio em terapia ocupacional social}

A partir de 2000, estabeleceu-se uma proposta para estágios de terapia ocupacional através da parceria entre o Núcleo USP/UFSCar do Projeto Metuia e a Associação Minha Rua Minha Casa (AMRMC). O objetivo específico desse estágio profissional é capacitar o graduando para atuar no território, em espaços comunitários e instituições sociais, contribuindo para o equacionamento das necessidades de grupos populacionais em processos de ruptura das redes sociais de suporte, a partir de intervenções terapêutico-ocupacionais. Compõem seu elenco de atividades: participação no planejamento, organização e desenvolvimento de atividades junto aos terapeutas ocupacionais e profissionais da equipe, registro sistemático das atividades, relatórios mensais, estudo e acompanhamento de caso, relatório final, leituras programadas, resenhas e discussão de textos, visitas a outras instituições e supervisões de terapia ocupacional (Núcleo USP/UFSCar, 2004).

\section{A Associação Minha Rua Minha Casa e seu contexto}

A Associação Minha Rua Minha Casa (AMRMC) foi criada em 1994 em parceria com membros do Pensamento Nacional das Bases Empresariais (PNBE) e da Organização de Auxílio Fraterno (OAF) - ONG (Organização não-

\footnotetext{
${ }^{2}$ O Curso de Graduação em Terapia Ocupacional da UFSCar está finalizando um longo processo de reestruturação curricular. O projeto pedagógico a ser implantado prevê disciplinas da área de terapia ocupacional social de caráter obrigatório e optativo.
} 
governamental) que atua desde 1946 junto à população em situação de rua. Localizada na Baixada do Glicério, região central da cidade de São Paulo, a Associação tem sido um centro de referência para o atendimento da população adulta em situação de rua, um espaço de convivência, acolhimento e realização de atividades de vida cotidiana - higiene pessoal e alimentação (BARROS et al., 2002).

O espaço possui características ímpares como a pouca iluminação por ser circundado por viadutos, o barulho de automóveis, a sujeira resultante da seleção de lixo realizada por catadores em suas imediações, a pobreza denunciada pelos cortiços e as relações de violência e tráfico. No entanto:

(...) se por um lado há este cenário adverso para instalação e manutenção da instituição, por outro, este mesmo espaço, aliado ao resultado da arquitetura urbana, confere à AMRMC um significado de 'lugar de passagem', em concordância com seus objetivos: ser um lugar de passagem, de transição entre uma vida na rua destituída de direitos e renegada à exclusão de toda a ordem (econômica, social) para uma vida com melhores condições. Ressalte-se que essas melhores condições não implicam, necessariamente, no fato de a pessoa estar fora das ruas, mas sim em instrumentalizá-la para que atue mais autonomamente e não se torne dependente de assistencialismo, bem como tenha maior acesso aos serviços disponibilizados (serviços básicos de saúde, serviços jurídicos, programas culturais, etc.) (LOPES et al., 2003, p.40).

A AMRMC conta com o trabalho de uma equipe técnica (composta por diferentes profissionais - assistente social, educadores sociais, arte-educadores, terapeuta ocupacional, psicólogo) e com a participação de voluntários. O suporte econômico é obtido através de um convênio com a Prefeitura Municipal de São Paulo, por doações, eventos para a captação de recursos e trabalhos voluntários.

\section{A população em situação de rua}

Considera-se uma pessoa em situação de rua quando esta utiliza logradouros públicos como local de habitação (onde dorme, alimenta-se e realiza as demais atividades cotidianas, incluindo, em muitos casos, até mesmo o traba1ho). É também considerado em situação de rua aquele que pernoita em albergues, pois também não possui moradia autônoma - seja alugada, como casa, pensão, república, ou própria (REIS; GALVANI, 2001). Contudo, nos deparamos com questões que vão além destas citadas, tais como o desemprego, a migração na busca de sobrevivência, o rompimento de vínculos familiares e afetivos, os quais favorecem uma sequiência de perdas e/ou transformações de valores, crenças e costumes; enfim, revelam processos de rupturas das redes sociais de suporte que inviabilizam a reintegração à sociedade, limitando, na maioria das vezes, a participação social e a interação ao circuito de instituições de atenção a essa população.

Os conceitos que Castel utiliza na discussão da estrutura e da inserção social são referências teóricas fundamentais para se compreender a realidade da população em situação de rua. Assim, a inserção deve ser analisada em dois eixos: o da relação de trabalho, com uma gama de posições do emprego estável à ausência completa de trabalho; e o da inserção relacional, também com um leque de posições entre a inscrição nas redes sólidas de sociabilidade e o isolamento social total. Esses dois eixos circunscrevem zonas diferentes do espaço social: zona de integração - onde se dispõe de garantias de um trabalho permanente e se mobiliza suportes relacionais sólidos; zona de desfiliação - nesse espaço se conjugam ausência de trabalho e isolamento social, implicando uma dupla ruptura das redes de sociabilidade e participação; zona de vulnerabilidade - que associa precariedade do trabalho e fragilidade relacional (CASTEL, 1994, 1997).

Trata-se, portanto, da atenção a pessoas sujeitas ao risco, à vulnerabilidade, no contexto da situação de rua, diante dos muitos processos 'macro e micro-sociais' que, em suma, revelam a precariedade do trabalho e a fragilidade relacional, os quais alimentam o terreno da desfiliação.

\section{$O$ encontro: passos para conhecer $e$ interagir}

Chegar na AMRMC, vem representando, para a maioria dos alunos, os primeiros passos no terreno da desigualdade e da exclusão que não fazem parte da nossa trajetória de classe e que, muitas vezes, nos permitem a ilusão de uma sociedade menos injusta. A primeira atividade proposta pelo estágio tem parecido simples aos estagiários em um primeiro olhar: observar a rotina da instituição, conhecer e verificar quem eram os freqüentadores da AMRMC e porque vinham para aquele espaço. Entretanto, aproximar-se concretamente das pessoas em situação de rua não é como receber, para um primeiro contato, um usuário que procura o técnico em um serviço de saúde em um ambiente protegido; demanda disponibilidades entre indivíduos extremamente díspares.

As indicações e discussões de leituras a respeito da população focalizada têm buscado fornecer respostas às dúvidas e fortalecer os primeiros passos diante do contato com uma realidade muitas vezes ignorada pelos alunos. Além disso, a realização das visitas institucionais aos equipamentos que fazem parte da rede de apoio a essa população, tais como os albergues, a moradia provisória e 
até mesmo as famosas "bocas de rango" (locais que oferecem almoço e/ou jantar a baixo custo ou gratuitamente), complementa a aproximação com os usuários da AMRMC e com o cotidiano das pessoas em situação de rua. Podese, então, estabelecer um diálogo um pouco mais próximo da vida nas ruas.

Outro aspecto que tem permeado o início dos estágios é a procura pela diferenciação do papel do terapeuta ocupacional diante dos demais técnicos, acompanhada pela formulação do que é a atuação da terapia ocupacional junto às pessoas em situação de rua, bem como do estranhamento com relação à saúde inserida em problemáticas mais amplas do que as de costume. É importante esclarecer que a equipe técnica pauta-se por diretrizes e formulações de Paulo Freire (1985), especialmente, na sua visão de educadores sociais necessários. De maneira geral, percebe-se, no decorrer do estágio, que os questionamentos acerca do papel não eram uma especificidade da categoria profissional do terapeuta ocupacional e sim uma demanda dos técnicos como um todo, que constantemente discutem as razões de estarem e permanecerem naquele espaço de trabalho.

A partir do conhecimento dos mecanismos da instituição, do seu funcionamento, das especificidades da população atendida foi possível caminhar para um segundo momento da experiência do estágio.

\section{O processo de interação: o surgimento das histórias fragmentadas}

Esse momento referia-se à participação no planejamento, organização e desenvolvimento de atividades junto com a terapeuta ocupacional. A necessidade de interagir e de conhecer as pessoas pôde ser suprida através da inserção em dois dos grupos de atividades coordenados pela terapia ocupacional da AMRMC: a Mesa de Fios e a Unidade Produtiva.

\begin{abstract}
A Mesa de Fios é uma oficina realizada num espaço coletivo, utilizando materiais diversos como: lã, linha, teares, agulhas de crochê, tricô, bordado, panos, entre outros. A proposta é aberta e oferece diferentes possibilidades de participação: a quem quiser saber o que está acontecendo, fazer algo, conversar, aprender uma técnica, costurar a calça que rasgou ou pregar o botão que caiu, fazer um presente, confeccionar algo que está precisando, falar de seus projetos de vida ou para buscar sua realização. A partir dos contatos estabelecidos, surgem demandas que são, quando possível, acompanhadas individualmente. Esta proposta também possibilita a divulgação e/ou o encaminhamento para outros programas da AMRMC (BARROS et al., 2002, p.5).
\end{abstract}

Através desta "porta de entrada", passou-se à divulgação da proposta da Unidade Produtiva, que é um programa de geração alternativa de renda.

\begin{abstract}
Propõe-se a ser um primeiro espaço de acolhida para o artesão em situação de rua. Oferecendo espaço físico para trabalho e armários onde possam ser guardados materiais e ferramentas, buscando, com isso, contribuir para a reorganização de seu esquema de trabalho e para sua reorganização pessoal. Além disso, tem o intuito de ser um nucleador, formando um grupo em que possam ser tratadas questões que surjam em decorrência do uso em conjunto de um mesmo espaço para trabalho, da relação que cada integrante estabelece com sua produção e também das expectativas e projetos que cada integrante possui e/ou queira construir (REIS et al., 2003, p.2).
\end{abstract}

Na Unidade Produtiva, como é proposto um vínculo próximo entre participantes e estagiários, também é possível realizar identificação de demandas e triagens para outros programas ou atendimentos realizados pela AMRMC ou fora dela, tais como cursos, atendimentos médicos, entre outros. Além disso, nesse espaço, os estagiários têm redescoberto o uso da atividade como um meio facilitador para a aproximação das pessoas e para o conhecimento de suas necessidades.

Com base nesse contato e no conhecimento de histórias de vida que revelavam, ainda que de maneira fragmentada, compreendeu-se a fragilidade dos vínculos, as rupturas existentes e a dinâmica de passagem por diversos lugares, uma situação constante para a população em situação de rua. Já, as dificuldades trazidas em ouvir histórias centradas na violência, miséria, revolta, quebra de relacionamentos familiares, exclusão, foram trabalhadas com o acompanhamento e a supervisão do Núcleo USP/ UFSCar no sentido de contextualizar e preparar a atuação do estagiário.

\section{A relação com o ‘outro’: o vínculo e as histórias de vida}

Outra proposição desse estágio tem sido a solicitação da realização de um estudo de caso e do acompanhamento de um usuário do serviço, identificado como situação emblemática, exercitando uma reflexão que possibilite a conexão entre os estudos teóricos e a experiência singular concreta. Solicitação nada simples diante das frágeis relações que as pessoas em situação de rua estabelecem, visto que, para realizar um estudo de caso e um acompanhamento, é necessário o embasamento na relação e no vínculo com o 'outro'.

A inconstância da dinâmica das ruas e as idas e vindas das pessoas na AMRMC e nas atividades propostas fazem com que o aluno, muitas vezes, não perceba que, na convivência diária, muitas histórias de vida se desvelam: a mulher que trabalhava como catadora de latinhas, dormia 
na rua e não tinha nenhuma família; os boatos sobre o jovem que não tinha dinheiro para voltar para sua casa no sul do país e, por isso, havia enlouquecido; o velho nordestino abandonado pelos filhos; a jovem mulher que tentava se reerguer após a confirmação de contrair o vírus HIV; o "recém-deslocado", aquele que vai para as ruas pela primeira vez, conforme Snow e Anderson(1998), e a procura incessante de um emprego; entre tantas outras.

Por meio dessas histórias, da relação durante o convívio na rotina da AMRMC e no espaço da Unidade Produtiva, tem sido possível ao estagiário compreender o 'outro' diante de suas necessidades e dificuldades estabelecendo relações que produzem ações e o vínculo como a base para o trabalho, sendo 'relação', termo que dá significado a palavra 'social', uma relação entre as pessoas, um fator primordial em uma intervenção terapêutico-ocupacional.

A história de vida, ao ser contada, tem sido uma atividade de imensa riqueza: o ato de revelar e compartilhar a própria história. Isto, acompanhado do potencial de significação e ressignificação da atividade, bem como da vinculação estabelecida, favorece a apropriação da vida singular e a elaboração de condições e possibilidades para sua continuidade em patamares mais autônomos.

Portanto, acredita-se que, nesse momento, o estagiário tem sido o instrumento e o aprendiz, o recurso facilitador do desenvolvimento desta atividade e atuação, que busca, dentre outras coisas, tramar, artesanalmente, vínculos mobilizadores de transformações. Transformações estas que acontecem tanto no indivíduo como no profissional e favorecem a composição da prática de um novo profissional, de um novo terapeuta ocupacional.

\section{Resultados: compreendendo a intervenção em tera- pia ocupacional social}

Muitas são as dificuldades da intervenção em terapia ocupacional social diante da problemática, do contexto social que se busca compreender; logo, exige do profissional o exercício de reconhecer os próprios valores, colocá-los de lado, sem, é claro, ignorá-los, para que possa entender as histórias de vidas reveladas, bem como o contexto em que são produzidas; estabelecendo, assim, uma relação de respeito e aprendizado entre uma realidade de caráter coletivo que permanece desigual, injusta e excludente e uma outra de caráter individual, rica e de enorme complexidade, que muda constantemente e precisa continuamente ser redescoberta.

As intervenções terapêutico-ocupacionais se deram nos âmbitos de acompanhamento, troca de experiências, reorganização pessoal e de esquemas de trabalho, incentivo aos desejos e construção de projetos de vida, fatos obtidos como resultados concretos a partir da riqueza das informações reveladas nas histórias de vida.

Com o acompanhamento e o estudo de caso, foi possível utilizar a escuta como recurso para a intervenção, a qual teve um significado importante diante das possibilidades de interação para a construção de algumas redes de suporte; foi possível, também, compreender que uma demanda apreendida dentro de um processo de vinculação é muito mais consistente e verdadeira. Assim, tecer redes de suporte diante de processos de desfiliação faz-se necessário, e isto demanda intervenções terapêuticoocupacionais que promovam uma atenção e uma busca pela maior autonomia da população em situação de rua.

\section{Conclusões: a teoria e a prática favorecendo a forma- ção do terapeuta ocupacional}

Refletir sobre a construção de uma proposição prática a partir do aprendizado e do reconhecimento das demandas do sujeito e do desenvolvimento da capacidade deste em buscar soluções próprias e criativas para suas questões, tornando a técnica dependente da interpretação e da apreensão da realidade, tem proporcionado o encontro dos fundamentos para uma intervenção em terapia ocupacional em consonância com necessidades sociais concretas. Sabemos que o terapeuta ocupacional no campo social soma-se a outros profissionais na busca de vencer o desafio de estabelecer redes sociais de suporte para uma população excluída que aumenta a cada dia. Assim, enxergar as demandas desta população e contribuir para o equacionamento de suas necessidades nos leva a propor intervenções terapêutico-ocupacionais em ações extraclínicas e territoriais.

O oferecimento do suporte teórico-prático é extremamente importante para o aluno-estagiário que busca, neste momento de formação, o elo entre a teoria e a prática profissional. Temos a certeza de que esta vivência deve compor a formação acadêmica do terapeuta ocupacional. Os conteúdos teóricos são rigorosamente imprescindíveis à agenda para a formação de profissionais no século XXI; as experimentações práticas devem ser articuladas com aqueles conteúdos. O estágio profissional na área deve compor o elenco de opções a serem oferecidas de acordo com as necessidades da população e dos interesses e identificações do aluno.

Estabelecer estas reflexões nos desafia a pensar estratégias para a produção de conhecimento, intervenção profissional e formação acadêmica que respondam às mudanças da saúde e da sociedade do século XXI. 
Agradecemos às colegas Denise Dias Barros, Debora Galvani e Marta Carvalho de Almeida pela parceria nas atividades do Núcleo USP/ UFSCar do Projeto Metuia na Associação Minha Rua Minha Casa, imprescindível para este trabalho.

LOPES, R. E.; PALMA, A. M., REIS, T. A. The theoretical-practical experimentation of an Occupational Therapy student in social field: an experience with homeless people. Rev. Ter. Ocup. Univ. São Paulo, v. 16, n. 2, p. 54-61, maio/ago., 2005.

\begin{abstract}
: almost after fifty years of existence of occupational therapists' programs in brazil, the question of the link between practice and theory remains as the central challenge for a better professional education. in various fields or areas of intervention the occupational therapist's academic education has been transformed, due to technological advances and knowledge, due to the public policies that are in continuous process of establishment or, still, due to the great target of action from non-governmental organizations that are part of the population groups' trajectory to wich brazilian occupational therapy dedicate themselves. on the other hand, the challenges of teh unequal and complex social reality demand a prepared professional to act/intervene in different society sectors, in situations that exceed the established space, as defined by the "health and illness" concepts. the studies and debates about the composition of the graduation's curricular components and the minimum standards have opened possibilities for the inclusion of the new areas/thematics, through courses whose contents search to endow the occupational therapist with capacities and abilities that allows them to understand and implement actions in the social field. in this perspective, this is an essay about the experience of the professional training in occupational therapy with homeless people, offered to Universidade Federal de São Carlos' students. the analysis and conclusions reported reinforce the defense of the importance of social occupational therapy as a curricular content course in the academic qualification of occupational therapists, and point to the connection between profession fudamentals and different possibilities of intervention.
\end{abstract}

KEY WORDS: Education, higher. Social responsability. Occupational therapy/trends. Occupational herapy/education. Curriculum.

\title{
REFERÊNCIAS
}

BARROS, D.D.; GHIRARDI, M. I. G.; LOPES, R. E. Terapia ocupacional social. Rev Ter Ocup Univ São Paulo, São Paulo, v. 13, n. 2, p. 95-103, 2002.

BARROS, D. D.; LOPES, R. E.; GALHEIGO, S. M. Projeto Metuia - terapia ocupacional no campo social. Mundo Saúde, São Paulo, v. 26, n. 3, p. 365-369, 2002.

BARROS, D. D.; LOPES, R. E.; REIS, T. A. M.; GALVANI, D. População adulta em situação de rua: resgatando percursos e construindo projetos - a experiência do Projeto Metuia. In: CONGRESSO BRASILEIRO DE EXTENSÃO UNIVERSITÁRIA, 1., João pessoa, 2002. Anais. João Pessoa: Universidade Federal da Paraíba - Pró-Reitoria de Assuntos Comunitários, 2002. CD-ROOM.

CASTEL, R. Da indigência à exclusão, a desfiliação. Precariedade do trabalho e vulnerabilidade relacional. In: LANCETTI, A. (Org.).
Saúde loucura, n. 4. São Paulo: Hucitec, 1994. p. 21-48.

CASTEL, R. As transformações da questão social. In: BELFIOREWANDERLEY, M.; BÓGUS, L.; YAZBEK, M. C. (Org.). Desigualdade e a questão social. São Paulo: EDUC, 1997. p. 161-190.

COORDENAÇÃO DO CURSO DE GRADUAÇÃO EM TERAPIA OCUPACIONAL DA UNIVERSIDADE FEDERAL DE SÃO CARLOS. Catálogo do Curso de Graduação em Terapia Ocupacional. São Carlos: UFSCar, 2003. 39 p.

FREIRE, P. Educadores de rua: uma abordagem crítica. São Paulo: Projeto: Alternativas de Atendimento a Meninos de Rua - UNICEF, 1985.

HAHN, M.; LOPES, R. E. Diretrizes para a formação de terapeutas ocupacionais - percursos e perspectivas. Pro-posições, Campinas, v. 14, n. 1, p. 121-39, jan./abr., 2003. 
LOPES, R. E. et al. A. A experimentação teórico-prática. Rev. Ter. Ocup. Univ. São Paulo, v. 16, n. 2, p. 54-61, maio/ago., 2005.

LOPES, R. E. Cidadania, políticas públicas e terapia ocupacional. 1999. $539 \mathrm{f}$. Tese (Doutorado)-Faculdade de Educação, Universidade Estadual de Campinas. Campinas, 1999.

LOPES, R. E. A formação do terapeuta ocupacional: considerações sobre a trajetória de 50 anos no Brasil. In: CONGRESSO NORTENORDESTE DE TERAPIA OCUPACIONAL, 5., Fortaleza, out. 2004. Fortaleza, 2004a. 15 p.

LOPES, R. E. Estudos e discussões em terapia ocupacional no campo social. Projeto de extensão do Departamento de Terapia Ocupacional da UFSCar. São Carlos: UFSCar, 2004b.

LOPES, R. E.; BORBA, P. L. O.; REIS, T. A. M. Um olhar sobre as trajetórias, percursos e histórias de mulheres em situação de rua. Cad Ter Ocup UFSCar., São Carlos, v. 11, n. 1, p. 38-53, 2003.

Recebido para publicação: 22/04/2005 Aceito para publicação: 22/05/2005
REIS, T. A. M.; GALVANI, D. TO no campo social: relato de uma experiência com população adulta em situação de rua. In: CONGRESSO BRASILEIRO DE TERAPIA OCUPACIONAL, 7., Porto Alegre, 2001.

REIS, T. A. M.; GALVANI, D.; BARROS, D. D.; LOPES, R. E. Núcleo produtivo - lados del trabajo con población adulta de calles en São Paulo - Brasil. In: CONGRESO ARGENTINO DE TERAPIA OCUPACIONAL, 6., 2003, Buenos Aires. Anales. Buenos Aires, 2003.

SNOW, D. A.; ANDERSON, L. Os desafortunados: um estudo sobre o povo de rua. Petrópolis: Vozes, 1998.

UNIVERSIDADE FEDERAL DE SÃO CARLOS; UNIVERSIDADE DE SÃO PAULO. Programa de estágio. São Carlos: Núcleo USP/UFSCar, 2004. 